\title{
Conversas invisíveis: assuntos falados, mas não ouvidos em consultas ginecológicas
}

\author{
Invisible conversations: subjects spoken but unheard \\ in gynecological visits
}

Stela Nazareth Meneghel (https://orcid.org/0000-0002-7219-7178) ${ }^{1}$

Daniela Negraes Pinheiro Andrade (https://orcid.org/0000-0003-4580-5307) ${ }^{2}$

Lilian Zielke Hesler (https://orcid.org/0000-0001-9363-2709) ${ }^{3}$
${ }^{1}$ Escola de Enfermagem, Universidade Federal do Rio Grande do Sul. R. São Manoel 963, Rio Branco. 90620-110 Porto Alegre RS Brasil.

stelameneghel@gmail.com

${ }^{2}$ Escola de Saúde,

Universidade do Vale do Rio

dos Sinos. São Leopoldo RS

Brasil.

${ }^{3}$ Programa de Pós-

Graduação em Enfermagem,

UFRGS. Porto Alegre RS

Brasil.

\begin{abstract}
This is a qualitative study based on the theoretical-methodological assumptions of the Conversation Analysis (CA) that describes and analyzes face-to-face interactions between three nurses and seven users of primary health care services during the cytopathological test collection visits. The descriptions and analyses were based on excerpts from the audio-recorded interactions during the nursing visits and transcribed based on the CA conventions. Data microanalysis from an emic perspective allowed identifying interactional situations of (mis)alignment, (dis)affiliation, repairs, and sensitive issues, and lack of listening to specific topics by nurses while conducting visits. Thus, signs of suffering, malaise, or violence were not explored, and care was not enhanced. The study shows that the cytopathological test collection visit can be a space to listen to issues related to sexuality and investigate the presence of violence against women. The dissemination of these findings and this methodology among public health and nursing professionals may stimulate a reflection on their communicative abilities, contributing to improved quality of care in health services. Key words Conversation Analysis, Face-to-face interaction, Violence, Women health, Public Health
\end{abstract}

Resumo Estudo qualitativo baseado nos pressupostos teórico-metodológicos da Análise da Conversa $(A C)$ que descreve e analisa interações face a face entre três enfermeiras e sete usuárias de serviços de atenção primária em saúde, ocorridas durante consultas para coleta do exame citopatológico. As descrições e as análises pautaram-se nos excertos das interações gravadas em áudio durante as consultas de enfermagem e transcritas com base nas convenções da AC. A análise micro dos dados realizada a partir da perspectiva êmica permitiu identificar situações interacionais de (des)alinhamento, (des)filiação, reparos e temas delicados, além da ausência de escuta de tópicos específicos por parte das enfermeiras ao conduzirem as consultas. Assim, sinalizações de situações de sofrimento, mal-estar ou violências não foram exploradas, deixando de potencializar o cuidado. $O$ estudo demonstra que a consulta para coleta de exame CP pode ser um espaço para ouvir questões relacionadas à sexualidade e investigar a presença de violência contra a mulher. A divulgação destes achados e desta metodologia junto aos profissionais de saúde coletiva e de enfermagem pode estimular a reflexão dos mesmos sobre suas habilidades comunicativas, contribuindo para melhorar a qualidade da atenção nos serviços de saúde.

Palavras-chave Análise da Conversa, Interação face a face, Violências, Saúde da Mulher, Saúde pública 


\section{Introdução}

O tema da relação médico-paciente ou profissional de saúde-usuário é central para a compreensão dos limites e potencialidades da prática clíni$\mathrm{ca}, \mathrm{e}$ os achados de pesquisas neste campo podem ser estendidos às demais profissões da saúde, inclusive a enfermagem.

A consulta ginecológica de enfermagem constitui ou deveria constituir um encontro dialógico $^{1}$ ou uma rede de conversações ${ }^{2}$ possibilitando um espaço de conversa entre profissionais de enfermagem e usuárias de serviços de saúde. A escuta sensível possibilita ouvir o que as pessoas falam e como falam, procurando entender o que as faz sofrer. Porém, as práticas de saúde, incluindo a consulta médica e de enfermagem, ainda são profundamente afetadas e impregnadas pelo modelo hegemônico tecnocrático biologicista, medicalizador e, até mesmo, moralista ${ }^{3}$.

$\mathrm{O}$ exame colpocitológico (CP) ocorre no interior do espaço interacional da consulta de enfermagem, ambos potencialmente plurais, e segue a orientação de um protocolo, que orienta a formulação de perguntas e ações a serem realizadas no ato. O cumprimento estrito do protocolo burocratiza as conversas produzidas nas consultas para coleta de $\mathrm{CP}$, na medida em que se restringe ao cumprimento de um mandado institucional em que os procedimentos são organizados em rotinas.

Profissionais de saúde e pacientes, mesmo quanto tem origem social e cultural comum, tendem a ver os problemas de saúde de modos diferentes, os primeiros pautam-se na racionalidade científica e os segundos procuram explicar a perturbação que os afetam em um momento particular, além de usarem concepções holísticas de saúde e doença. As consultas são conduzidas em um misto de linguagem cotidiana e jargão técnico em que se usam diferentes linguagens para expressar o desconforto e traduzir sintomas e sinais em patologias e em prescrições ${ }^{5}$.

As relações entre profissionais e usuários nos serviços de saúde costumam ser formais, hierárquicas e com tendência a reproduzir padrões pré-definidos ${ }^{6}$. Pode-se considerar que um desses padrões é o linguajar generificado, no qual gênero é entendido como um conjunto de normas e prescrições que orientam as condutas masculinas e femininas na sociedade. Segundo Joan Scott ${ }^{7}$, gênero constitui uma hierarquia de poder entre homens e mulheres, pautada no binarismo sexual e na heteronormatividade compulsória. Como a socialização de gênero acontece em todos os âmbitos da cultura e opera nos indivíduos desde o nascimento, os profissionais de saúde tendem a reproduzir acriticamente estes estereótipos nas interações sociais e profissionais.

A ascendência dos profissionais em relação aos pacientes faz com que nas conversas caiba a eles a prerrogativa de fazer as perguntas, escolher o tópico da conversa, selecionar quem irá falar, iniciar e finalizar sequências de ações interacionais, sancionar contribuições julgadas inadequadas. A assimetria entre os interagentes, com propensão de exercício de poder por parte de representantes institucionais também aparece na recorrência de atrasos ou mesmo na supressão de respostas a perguntas realizadas por pacientes que, muitas vezes, não se sentem autorizados a contar aos profissionais de saúde os sofrimentos que os afligem ${ }^{8}$ ou que os relatam e não são ouvidos.

Considera-se, então, como propõe Ayres ${ }^{1}$ que na relação entre profissionais de saúde e usuários é preciso fugir de uma objetivação dessubjetivadora ancorada na tecnologia e apostar no cuidado, entendido como ação prática, mediada pela palavra, de sujeitos que cuidam e são cuidados. Ainda, segundo Ayres ${ }^{9}$, para que essa relação entre profissionais de saúde, incluindo os da enfermagem, e usuários seja entendida como cuidado é preciso que se coloque o sentido e o êxito instrumental das técnicas - nesse caso o exame citopatológico - a serviço dos projetos de felicidade daqueles que demandam atenção. Essa abertura para o outro, que acontece por meio da escuta e do diálogo constitui o acolhimento, recurso fundamental para que o desejo dos e das usuárias possa emergir e tornar-se o norte das intervenções propostas.

Um dos pressupostos aventados ao iniciar este trabalho era de que a consulta de enfermagem constitui um espaço onde os relatos de questões ligadas à sexualidade e violências poderiam aparecer, na medida em que as mulheres se sentissem à vontade para narrar tais eventos, como observado em outros estudos ${ }^{10}$.

Os objetivos deste artigo, que faz parte de uma pesquisa maior sobre a equidade de gênero na atenção a mulheres ${ }^{11}$ foi o de analisar conversas e identificar relatos que poderiam estar indicando uma queixa, um sinal ou um pedido de ajuda, incluindo situações de violência. Entende-se que a divulgação destes achados junto a profissionais do campo da saúde pode estimular a reflexão dos mesmos sobre suas habilidades comunicativas, contribuindo para a melhoria da qualidade da atenção nos serviços de saúde. 


\section{Trajeto metodológico}

Este é um estudo qualitativo conduzido com base nos pressupostos teórico-metodológicos da Análise da Conversa ou teoria da fala-em-interação ${ }^{4}$, que analisou interações naturalísticas ${ }^{12}$ entre enfermeiras e usuárias durante a consulta de enfermagem focada na coleta do CP.

Para este artigo foram selecionadas conversas nas quais se observam dificuldades de escuta por parte das enfermeiras, o que se evidencia, por ocorrência de desalinhamento ${ }^{13}$ e/ou desafiliação $^{13}$ entre profissionais e usuárias, reparos ${ }^{14}$, risadas não compartilhadas e omissão de respostas a perguntas ou queixas, configurada pelo silêncio ou troca de assunto. Também foram incluídas conversas em que emergiram temas tratados como delicados pelas participantes e falas em que se observam as usuárias indicando algo que pode ser entendido como início de relato de violência, mas que não foram explorados pelas profissionais.

O conceito de (des)alinhamento ${ }^{13}$ refere-se à ação responsiva de um interagente diante da ação projetada no turno de fala imediatamente anterior ao da resposta. (Des)afiliação ${ }^{13}$ diz respeito à maneira como o interagente demonstra posicionar-se em relação a algo dito por seu interlocutor, podendo haver concordância com o que foi dito anteriormente (afiliação interacional) ou discordância (desafiliação interacional). Reparo ${ }^{14}$ acontece quando, em uma interação, os participantes deparam-se com problemas na produção da fala (sua própria ou do outro), na audição ou no entendimento do que foi dito, havendo, portanto, quebra do "fluxo da conversa".

Os assuntos delicados são observados quando há mudança de orientação dos participantes e transparece na maneira como o interagente produz seu turno de fala ou ação corporificada ${ }^{15}$, isto é, um gesto, uma expressão facial, um movimento respiratório visível, acompanhada ou não de fala. Evidencia-se mudança de orientação na interação na presença de hesitação, de aumento ou diminuição de volume de voz, de aceleração ou desaceleração da produção da fala, da substituição ou supressão de termos ${ }^{16}$.

Esta investigação pauta-se nas conversas ocorridas em consultas no período de janeiro a dezembro de 2016, em encontros face a face em que participaram três enfermeiras que atuam em serviços de atenção primária de um município do interior do Rio Grande do Sul (RS) e 26 mulheres que procuraram os serviços para realização de CP. Neste estudo foram selecionadas sete mulhe- res, cujos relatos traziam elementos linguísticos e conteúdos relacionados à temática. Adotou-se uma perspectiva êmica, isto é, com base naquilo que os participantes da conversa tornam relevante nos seus turnos de fala ${ }^{17}$.

A geração de dados foi realizada por meio de gravação em áudio dessas interações, transcritas de maneira fidedigna ao modo com que foram verbalizadas, com base nas convenções utilizadas pelos analistas da conversa ${ }^{18}$. As transcrições incluem os silêncios e as pausas; sinalizam risadas, hesitações, sons emitidos em inspirações profundas (hhhh), emissão de palavras truncadas ou incompletas, falas coconstruídas ou sobrepostas, quando um dos falantes inicia seu turno e o anterior ainda não completou o seu, assinaladas pela presença de colchetes. A AC registra os continuadores comumente usados em conversas (aham, hum, $\mathrm{mm}$ ), mantém ausência de concordância, pluralização e de "r" nos verbos no infinitivo, marca o tom conferido a palavras ou partículas, usando convenções para indicar prolongamento de sílabas (::), diminuição $\left(^{\circ}\right)$ no tom de voz, setas para indicar entonação ascendente ou descendente e a marcação $(<>)$ para indicar frase pronunciada em tom de voz mais baixo ${ }^{19}$.

As enfermeiras são referidas como E1, E2 e E3 e as mulheres como M1, M2, M3 etc. Neste artigo, procedem-se às análises de sete excertos de interações referentes às enfermeiras: E2 e E3 em encontros com as usuárias: M8, M9, M10, M13, M15, M16, M23.

Este trabalho foi aprovado em Comitê de Ética em Pesquisa/UFRGS e as gravações das consultas foram realizadas com o consentimento formal de todas as participantes.

\section{Ruídos, silêncios, assuntos falados e não ouvidos}

A interação entre enfermeiras e usuárias na consulta ginecológica pode ser afetada pelas dificuldades das mulheres em conversar sobre aspectos íntimos de suas vidas e questões relacionadas à sexualidade, incluindo mal estar, dor e violências. Neste trabalho, emergiram relatos possivelmente relacionados à sexualidade e violências que acarretaram sofrimento físico e emocional. Porém, algumas destas revelações e queixas, não foram ouvidas pelas profissionais que atenderam as mulheres e é sobre estas situações que esta análise foi produzida.

As contribuições interacionais de participantes em encontros clínicos podem expressar concordância ou discordância, alinhamento ou desa- 
linhamento ou, ainda afiliação ou desafiliação em relação a alguma ação interacional realizada pela interlocutora. Por um lado, as usuárias podem despender tempo se justificando ou se desculpando por não terem cumprido algum preceito ou norma, mas por outro lado, podem ignorar o que foi proposto pela enfermeira por meio de produção de silêncio, mudança de assunto, ou, até mesmo, contestando ou negando o que foi dito pela profissional no(s) turno(s) de fala anterior(es). De modo semelhante, as profissionais podem usar os mesmos recursos interacionais em respostas a turnos de fala produzidos por usuárias ${ }^{14}$. Salienta-se, porém, que, em contextos de consultas para coleta de CP, assim como em cenários institucionais, as enfermeiras estão em posição de maior poder e autoridade em relação às usuárias.

Percebe-se a ocorrência de desalinhamento e desafiliação no Excerto 1, parte da conversa entre E2 e M10, usuária de 62 anos com histórico de dez gestações. Na linha 1, a enfermeira realiza uma pergunta que envolve o estado reprodutor atual da usuária:

Excerto 1: "Não tá grávida né ?" (M10, 62 anos, separada, nove filhos, um aborto espontâneo).

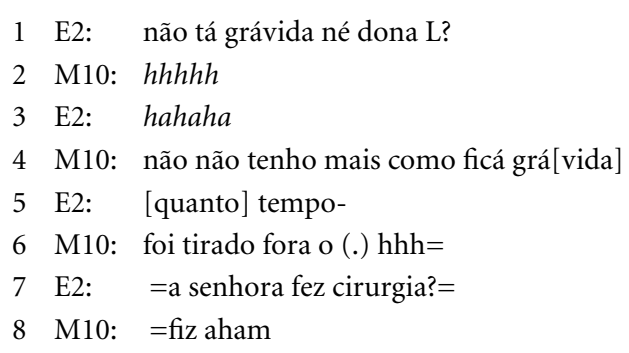

Observa-se que o formato da pergunta de E2, na linha 1 - "não tá grávida, né," é restritiva no sentido de que a resposta preferida é negativa. Ao realizar a pergunta em um formato negativo, E2 limita a ação responsiva da usuária, impondo a ela a obrigação interacional, e, portanto, social, de ter que prover explicações em caso de incongruência com a preferência expressa pela pergunta. Em lugar de "sim" (uma resposta despreferida) ou "não" (uma resposta preferida), a usuária expira com intensidade ( $h h h h)$, o que evidencia que sua resposta está em desalinhamento com a pergunta. O desalinhamento ocorre porque a ação realizada pela expiração está em desacordo com uma das regras que permeiam as interações sociais em que dada uma primeira ação de um determinado tipo (e.g., uma pergunta), a segunda ação de operar modo responsivo à primeira (e.g., uma resposta $)^{14}$. Neste caso, pode-se pensar que a expiração audível exibiu uma reclamação e a resposta da enfermeira é produção de riso.

O riso assim como o humor, é situado, isto é, depende do contexto e do compartilhamento de mundo entre os participantes do enquadre comunicacional. Nas circunstâncias em que não há problema interacional transparente, o riso convida o interlocutor a rir em resposta e funciona como amálgama para a construção de alianças entre os participantes e para a criação de laços de cumplicidade. Quando apenas uma das partes ri, há indícios de desafiliação na interação. Tomando-se a idade e o histórico da vida reprodutiva da usuária, cabe considerar que tanto a pergunta da enfermeira, quanto seu modo de lidar com a resposta da usuária não foi equânime, pois ela desconsidera o aspecto geracional de uma mulher que biologicamente não poderia mais estar grávida, fato trazido à tona pela própria usuária ("não tenho mais como ficá grávida").

O procedimento de esterilização é trazido à interação por M10 como parte da prestação de contas que ela está produzindo em resposta à pergunta da enfermeira. M10 se refere ao procedimento utilizando a voz passiva no tempo pretérito, o que sugere que o fato deu-se fora do âmbito de sua agentividade ${ }^{20}$. A usuária não nomeia $o$ que foi tirado de si (o útero), o que pode indicar, ou que ela desconhece o nome do órgão, ou que pronunciar o nome do órgão é algo problemático para ela. De qualquer modo, ela termina seu turno de fala produzindo uma expiração audível $(h h h)$, o que leva a inferir que ela está tratando do tópico como algo delicado e como uma reclamação sobre o que lhe acontecera (a remoção de seu útero).

Outro exemplo de ocorrência de desalinhamento e desafiliação pode ser averiguado no Excerto 2, em que M9 se mostra incomodada com o aspecto físico de sua barriga em função de um procedimento cirúrgico. O excerto inicia com a usuária chamando a atenção da enfermeira para sua região abdominal, por meio de uma solicitação de informação - "tu viu como ficou minha barriga", referindo-se ao "buraco" deixado na parede do abdômen e que se encontra dentro do campo de visão da enfermeira: 
Excerto 2: "Tranquilo uma titica" (M9, 40 anos, solteira, três filhos).

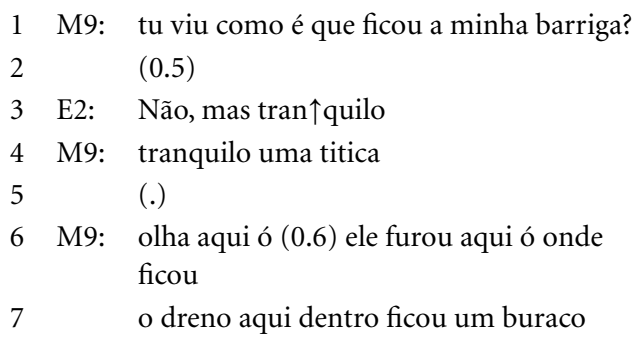

A pergunta realizada por M9 pede uma explicação, embora tenha um formato polar, cuja resposta é "sim" ou "não"21 e M9, ao dirigir a pergunta à enfermeira, inicia uma sequência interacional que abre a possibilidade para a sua interlocutora solidarizar-se a ela. Porém, E2 deixa passar a oportunidade de exercer empatia, uma das premissas do acolhimento. Em lugar disso, E2 parece tomar o rumo da mitigação e produz uma avaliação sobre a marca na barriga de M9, iniciada por uma oração adversativa (não, mas) e o adjetivo tranquilo, manifestando aceitabilidade ao procedimento. M9 contrapõe-se à avaliação produzida pela enfermeira (tranquilo uma titica), descreve o procedimento realizado "por ele", o médico, nomeia o resultado obtido como "buraco" e realiza uma acusação de má prática médica.

As marcas deixadas ou provocadas devido a procedimentos cirúrgicos, por conta de gravide$\mathrm{z}(\mathrm{es})$, parto(s), etc. parecem deixar inscritas nos corpos das mulheres o registro da função considerada ideal no universo simbólico do femini$\mathrm{no}^{22}$. Em situações de consulta ginecológica é comum elas tornarem relevante as marcas inscritas em seus corpos, como o fez M9. Porém, M9 não mostra a marca como uma conquista, mas como uma denúncia da iatrogenia produzida do médico que a atendeu.

Ainda refletindo sobre ocorrências de (des) alinhamento e/ou (des)afiliação em conversas entre enfermeiras e usuárias, traz-se o Excerto 3, que inicia com M16 aproveitando a consulta para esclarecer dúvidas acerca de um sintoma que a preocupa. É comum as usuárias relatarem sintomas em espaços voltados à prevenção, como os da coleta de CP, pela dificuldade de marcar consultas com ginecologista na APS ou pelo fato de que muitas vezes, elas não são ouvidas nas consultas médicas, ou se ouvidas, não são levadas a sério ${ }^{23}$ :
Excerto 3: "Eu tô tipo assim, como é que vou te dizer?" (M16, 36 anos, solteira, um filho).

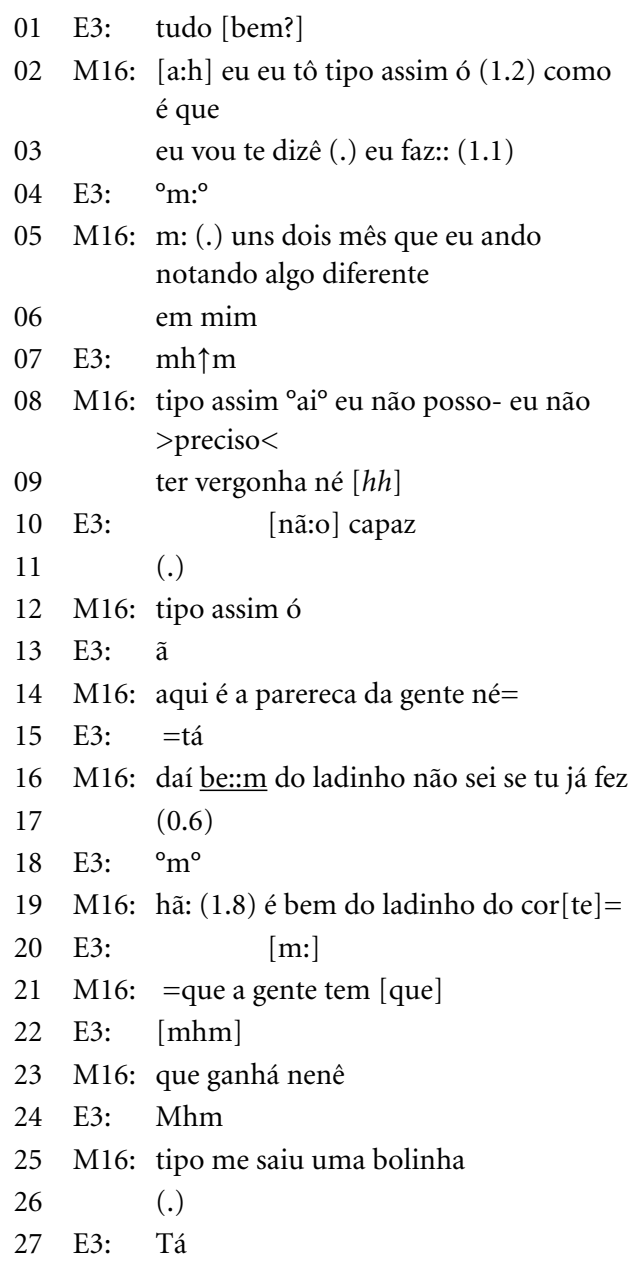

Com base no Excerto 3, vê-se que M16 toma o turno de fala de E3, na linha 1, não como saudação, mas como uma pergunta acerca de seu estado de saúde. Em resposta, M16 manifesta a percepção de algo anormal em si (linha 5), ao que a enfermeira responde com um continuador ou, nas palavras de Schegloff ${ }^{14}$, um "vá em frente." A manifestação da queixa é prefaciada por descontinuações de turno de fala, hesitações e expressões que operam de modo a atrasar a abordagem do tópico (linhas 2 e 3), o que demonstra que M16 está tendo dificuldade em expor o problema que torna-se ainda mais explícito quando a usuária traz à tona o sentimento de vergonha que a aflige ("tipo assim ai eu não posso eu não preciso ter vergonha, né"). E3 ratifica a solicitação de confirmação de M16 sobre não ser necessário sentir-se envergonhada ("nã:o capaz"), ação que 
não opera como tranquilizadora para M16, uma vez que ela segue atrasando o início do turno de fala, primeiro, por meio de uma micropausa e, em seguida, via expressão de retardamento de início de turno ("tipo assim ó”).

M16 começa a explicar, de maneira truncada, o problema de saúde que a preocupa referindose à parte do corpo onde o problema se localiza e citando o nome popularmente usado no Rio Grande do Sul para o órgão genital feminino (“perereca”). M16 utiliza a expressão "da gente”, que opera como forma inclusiva de expressar pertencimento. Assim, trabalha interacionalmente para aproximar sua interlocutora de si, compartilhando a identidade feminina, pelo fato de ambas serem mulheres. M16 invoca a posição anatômica de uma episiotomia e a experiência prévia de ter tido um bebê como uma nova possibilidade de compartilhamento de identidade ("não sei se tu já fez"). Dessa vez, E3 não se mostra afiliada à proposta de compartilhamento de experiência aludida por M16, uma vez que suas participações interacionais nesse momento são mínimas (linhas 18, 20, 22 e 24). A descrição do problema de saúde, fonte de preocupação para M16, ocorre apenas na linha 25 e trata-se de algo que ela refere como "bolinha" [que lhe saiu ao lado da episiotomia].

O Excerto $3 \mathrm{faz}$ transparecer, em dimensão micro, vários fenômenos macrossociais, a saber, é comum mulheres (a) sentirem vergonha de expor seus corpos em consultas de CP e (b) mulheres terem dificuldades para descrever seus problemas de saúde ginecológica. A análise do Excerto 3 corrobora o argumento de que a substituição do termo formal por outros de uso comum, popular ou infantil como forma das mulheres lidarem com sentimentos de dificuldade ou vergonha é um fenômeno recorrente em consultas de atendimento à saúde da mulher ${ }^{21}$. A ação de não verbalizar o nome do órgão genital feminino e fazer referência à vagina por meio de dêiticos (e.g., ali, lá embaixo) é outra estratégia interacional que mulheres lançam mão para lidar com sentimentos de embaraço. A ocorrência desse fenômeno pode ser averiguada no Excerto 4, que inicia com a enfermeira perguntando à usuária sobre alergia, fato que a usuária afirma estar ocorrendo:
Excerto 4: "Tô com alergia assim na (.)" (M13, 52 anos, solteira, um filho).

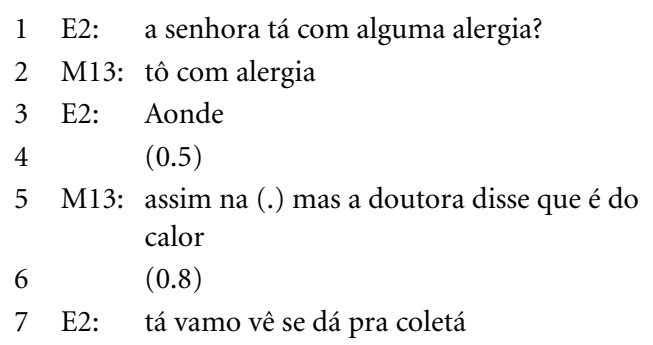

Diante da afirmação de M13, E2 solicita que a usuária especifique o local da alergia. Vê-se que após a solicitação da enfermeira, há uma pausa que opera como protelador de resposta e indica que o interagente toma a pergunta realizada no turno anterior como problemática ${ }^{24}$. Esse fato torna-se ainda mais notório quando M13 protela, por meio da palavra "assim na", a referência do local da alergia, apenas indicando gestualmente o local. A usuária exime-se de pronunciar o nome do órgão (vagina), acrescentando a atribuição feita pela médica para o incômodo proveniente da alergia ("mas a doutora disse que é do calor").

O Excerto 5 é um exemplo de como as queixas das usuárias tendem a permanecer inexploradas no sentido de instigarem a investigação de possíveis dificuldades que elas podem enfrentar no âmbito da sexualidade e conjugalidade. O excerto inicia com E3 questionando M23 sobre a ocorrência de dor intensa durante a coleta, confirmado pela a usuária. Por inferência, vê-se que E3 atribui a dor de M23 durante o procedimento ao ressecamento vaginal e a questiona a perduração do incômodo:

Excerto 5: "Na relação eu também tenho dor" ( M23, 30 anos, união estável, sem filhos).

\begin{tabular}{|c|c|c|}
\hline 1 & E3: & sentiu muita dor? (1.7) \\
\hline & M23: & é mhm (.) \\
\hline & E3: & $\begin{array}{l}>>\text { por que será que }<<\text { tá tão ressecado } \\
\text { sempre foi }\end{array}$ \\
\hline & & as $\uparrow \operatorname{sim}()$. \\
\hline & M23: & $\begin{array}{l}\text { tá- na relação eu também tenho dor } \\
\text { (2.6) }\end{array}$ \\
\hline & E3: & $\begin{array}{l}\text { tem que comprá um gelzinho (.) nas } \\
\text { farmácia tem os gelzinho }\end{array}$ \\
\hline & & $\begin{array}{l}\text { lubrificante vaginal pede (0.5) é bem } \\
\text { barato (.) que ajuda sabe }\end{array}$ \\
\hline & M23: & $\operatorname{Mhm}()$. \\
\hline 0 & E3: & $\begin{array}{l}\text { porque tá bem ressecado na parede da } \\
\text { vagina ali }\end{array}$ \\
\hline & & bem ressecadinho \\
\hline & & $(3.1)$ \\
\hline & & pode ter vestir \\
\hline
\end{tabular}


Em resposta à pergunta de E3, M23 introduz uma informação nova, qual seja, o fato de que "também sente dor na relação [sexual]" (linha 6). No turno subsequente, em lugar de perguntar sobre possíveis atribuições causais para a dor na relação sexual da usuária, que poderiam incluir desde cansaço, presença de infecção ginecológica, realização de sexo sem desejo ou, até mesmo, existência de violência conjugal, a enfermeira limita-se a oferecer uma solução prática para a queixa de M23 - a compra de um gel lubrificante. Para a oferta do gel, M23 produz uma resposta mínima, o que sugere desafiliação frente à solução apresentada por E3 para a sua queixa de dor na relação sexual.

Além da medicalização da sexualidade por meio da indicação de gel lubrificante, a dispensação de medicamentos foi mais ampla, como se pode constatar no Excerto 6, que inicia com a usuária fazendo uma autoavaliação referindo-se a si como "um caco":

Excerto 6: "Tô que é um caco" (M8, 44 anos, casada, dois filhos).

1 M8: então eu $\uparrow$ tô:: (1.1) como- como se diz o certo tô que

é um caco

$2 \quad(0.6)$

3 E2: tá que é um caco:

$4 \quad$ (.)

5 E2: mas tu já a doutora já entrou com al $\uparrow$ gu:m (.)

6 trata[mento pra ti]

7 M8: [ [ojá (.) ${ }^{\circ}$ jáo]

8 E2: Tá

$9 \quad(1.9)$

[linhas suprimidas]

10 M8: =e eu digo eu tenho que fazê alguma coisa pra:: $[\mathrm{me}]=$

11 E2: [é]

12 M8: =ajudá né [(fazê o retorno)]

13 E2: [é: e a-é: e a] doutora já te deu fluoxetina né

14 M8: Sim

Embora a autoavaliação feita pela usuária possa ser descrita como depreciativa, dado o campo semântico da palavra caco, M8 não especifica estar-se referindo ao seu estado físico ou emocional. E2 repete parte do turno de M8, mais precisamente, o trecho que traz a autoavaliação. Repetições parciais de turno podem realizar variadas ações conversacionais ${ }^{25,26}$, no caso do Excerto 6, a repetição do turno introduz um questionamento (linhas 5 e 6) referente à resolução do problema da usuária. O questionamento inicia de modo adversativo com foco na agentividade da usuária ("mas tu já") e, após ocorrência de reparo ${ }^{13}$, transforma-se em solicitação de confirmação com realocação de agentividade para a ginecologista de M8 ("a doutora já entrou com al $\uparrow$ gu:m (.)trata[mento pra ti]"). A confirmação da prescrição medicamentosa para o problema relatado pela própria usuária na forma metafórica de "caco" é tacitamente tratado pelas interagentes como de cunho emocional. Ao nomear o antidepressivo em seu turno de fala, a enfermeira solicita nova confirmação de que a médica ofertara tratamento para o sofrimento emocional de M8.

A prescrição de drogas antidepressivas em consultas preventivas como são as coletas para $\mathrm{CP}$, atesta a penetração da medicalização nas ações de promoção da saúde. O uso indiscriminado de drogas antidepressivas nas práticas e nos serviços de saúde em lugar de promover autonomia e autocuidado, faz emergir dependência e submissão via consumo de medicamentos como resposta para problemas de outras esferas ${ }^{27}$. Assim, questões econômico-financeiras, emocionais e, até mesmo, abusos de várias naturezas tais como violências sexuais e domésticas podem ser patologizadas, medicalizadas e invisibilizadas ${ }^{26,28}$.

Os Excertos 7 e 8 trazem conversas em que as mulheres fazem alusões a situações que sugerem a ocorrência de violência em ambientes domésticos. O Excerto 7 inicia com o relato das complicações de uma cesariana (linhas 1 a 4):

Excerto 7: "Eu sofria muito com meu ex-marido” (M10, 62 anos, separada, nove filhos e um aborto espontâneo).

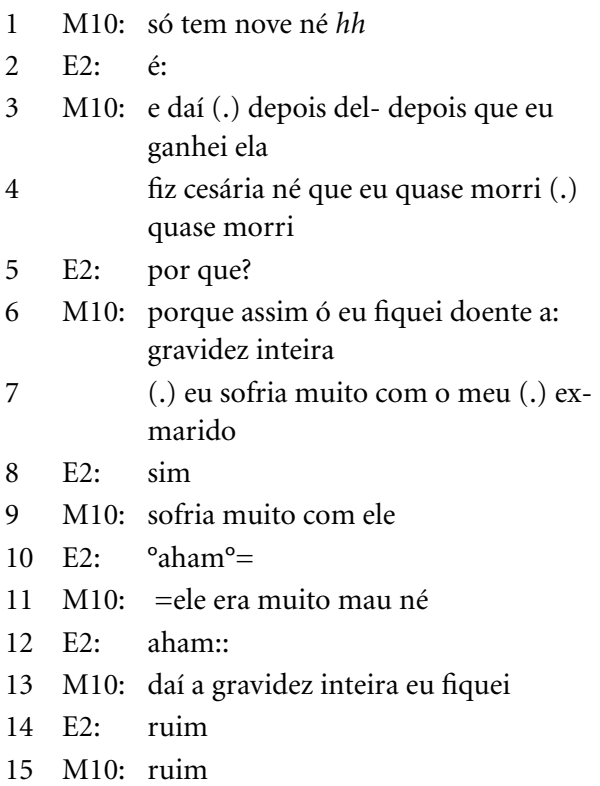


Ao tomar conhecimento da experiência limite relatada por M10, E2 pergunta o motivo do ocorrido, solicitando-lhe uma justificativa ou account $^{20}$. M10 atribui o fato ao seu mau estado de saúde durante a gestação e, após uma micropausa, acrescenta o sofrimento infligido pelo ex -marido. E2 atesta o recebimento de informação (sim, aham,aham), mas mostra-se desafiliada à M10 no sentido de responder à usuária, mesmo após M10 qualificar o ex-marido como "mau" e encerrar o turno de fala com o marcador discursivo "né”, frequentemente empregado como meio de buscar afiliação do interlocutor ${ }^{29}$. Em contraste, a enfermeira afilia-se à usuária quando o tópico da conversa desloca-se para o estado de saúde de M10 durante a gestação.

O fato de E2 abster-se de solicitar mais informações à avaliação que M10 faz de seu ex-marido sugere que ela escolhe ignorar a situação de abuso e/ou maus tratos na gravidez e na relação conjugal de M10, mantendo a história ignorada, não contada. O Excerto 7 reforça a suposição de que consultas para coleta de CP podem ser ambientes interacionais propícios para o relato de violências contra a mulher.

A análise do Excerto 8, na conversa entre E3 e M15, uma jovem de 19 anos, que ao ser posicionada na maca, manifesta estar sentindo medo em função do procedimento de coleta (trecho não mostrado). Na sequência, a enfermeira demonstra compreensão pelo sentimento expresso pela usuária (linhas 1 e 2), descreve o que vai fazer (linhas 3 e 4) e solicita que M15 a avise em caso de ocorrência de dor (linhas 8 e 9):

Excerto 8: "Quem te assustou dessa forma" (M15, 19 anos, união estável, dois filhos).

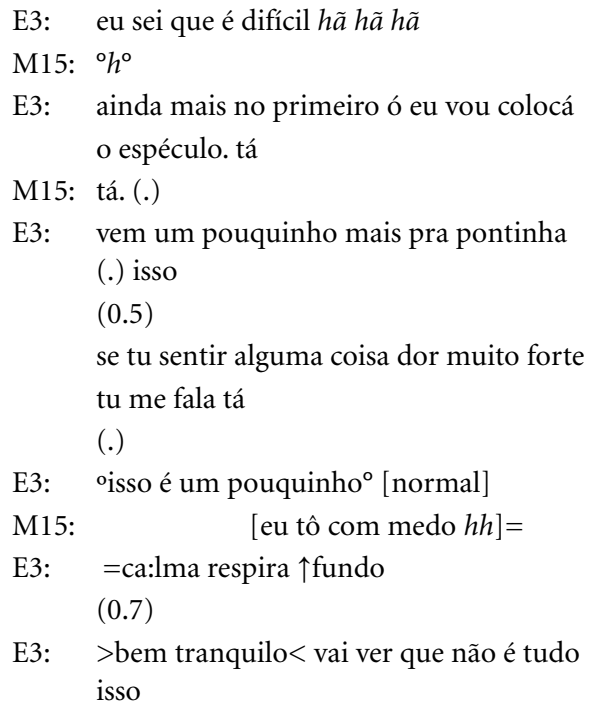

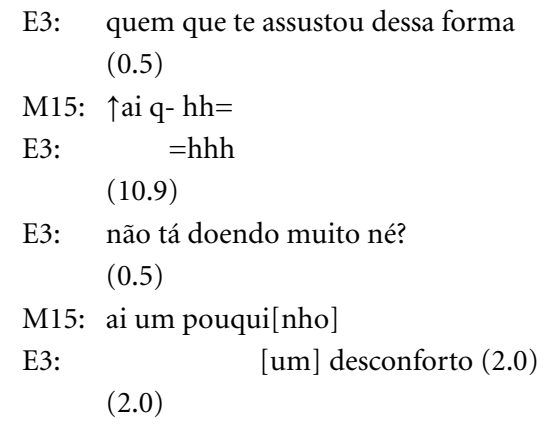

A usuária torna a manifestar medo (linha 12), ao que E3 responde instruindo-lhe sobre como controlar o sentimento ("ca:lma respira $\uparrow$ fundo"), minimizando o potencial atemorizante do procedimento ("vai ver que não é tudo isso") e, ao mesmo tempo, desvalorizando a queixa da usuária. Após uma pausa, E3, ao questionar M15 sobre a possibilidade de o medo ter sido causado pela iniciativa de uma terceira pessoa ("quem que te assustou dessa forma”), mostra atenção para a intensidade do temor exibido por M15, que responde com atraso e após pausa, inicia a elaboração de uma justificativa (“ $\uparrow a$ ai q-”), mas interrompe a fala e produz uma expiração audível (linha 19), ação que é repetida pela enfermeira, o que parece demonstrar certa afiliação entre as interagentes. Porém, E3 desperdiçou uma oportunidade para incentivar M15 a expor o motivo pelo qual se mostra visivelmente amedrontada. Tendo em vista que M15 começa a elaborar o questionamento feito por E3 sobre quem a teria assustado, é provável que, tivesse a enfermeira aberto a possibilidade de falar mais sobre o assunto, M15 pudesse ter revelado a causa de seu temor.

Refletindo-se acerca do que ocorre na interação em foco, vale aventar a possibilidade de que M15 possa estar em estado de estresse póstraumático, ou que tenha sofrido uma violência sexual. Nestas situações, as vítimas não toleram o contato físico, que lhe causa medo e repugnân$\mathrm{cia}^{30,31}$. Não se pode descartar, porém, que a dor e o temor possam ter sido desencadeados pelo próprio exame ginecológico, muitas vezes realizado sem o devido preparo ou de modo impositivo e abrupto, o que configura também uma violência institucional. Independentemente da rejeição ao exame e o medo evidenciado por M15 serem decorrentes de uma situação de violência, doméstica ou mesmo institucional, a causa de tais manifestações permanece invisível, uma vez que a usuária não chega a produzir fala que a descreva.

A invisibilização de queixas e sintomas que poderiam estar indicando violências, mas que 
não foram aventados pode dever-se ao fato de que alguns problemas são considerados de responsabilidade dos serviços, assim a presença de sinais e sintomas que remetem ao aparelho sexual feminino é ouvida e identificada quando indicativa de doenças como o câncer para as quais o serviço é referência, enquanto outros agravos, como as violências, embora constituam um grave problema de saúde pública, permanecem invisíveis mesmo quando há sinais de sua presença, desconsiderando-se a responsabilidade do setor saúde ${ }^{32}$.

Quando o horizonte normativo é a morfofuncionalidade e seus riscos, diz Ayres ${ }^{9}$, a escuta, dirigida como anamnese tradicional, será orientada para identificar um objeto de intervenção, e aspectos ligados à situação existencial das e dos usuários serão considerados secundários ou, até mesmo, percebidos como ruídos.

O modelo biomédico historicamente vigente na sociedade ocidental está ancorado na ciência, tecnologia, lucro econômico e nas instituições patriarcais. Este modelo opera na lógica da segmentação do corpo humano percebido como uma máquina, na visão das pessoas como objetos e na alienação do profissional em relação ao paciente. Acrescente-se a organização hierárquica, burocrática e autoritária do trabalho e a padronização dos procedimentos ${ }^{33}$.

As conversas analisadas sinalizam o quanto a enfermagem foi colonizada pelo modelo biomédico hegemônico, tecnocrático, pouco dialógico e hierárquico. Neste sentido, assuntos trazidos por pacientes considerados irrelevantes pelos médicos ou enfermeiros, sequer são ouvidos, queixas podem ser minimizadas ou desconsideradas e temas como sexualidade e/ou violências permanecem invisíveis. Além disso, é de longa data a medicalização de mulheres devido a sintomas produzidos pela violência doméstica ${ }^{34}$, além da supervalorização da tecnologia em detrimento das interações conversacionais e do diálogo.

\section{Considerações finais}

Este trabalho constituiu o desafio de utilizar um recurso metodológico potente - a Análise da Conversa -, ainda pouco explorado no campo da saúde, para analisar conversas produzidas entre profissionais e usuárias durante a consulta de enfermagem ginecológica. Estudo inédito mostrou que nem sempre as enfermeiras realizam uma escuta que atenda as demandas das mulheres, seja tornando suas histórias visíveis, seja demonstrando empatia para com seus receios e dificul- dades. Ocorrências de desalinhamentos e/ou desafiliações interacionais de parte a parte mostram ou que não há sensibilização das profissionais para demandas trazidas pelas usuárias ou que as soluções apresentadas pelas enfermeiras não são tomadas pelas usuárias como satisfatórias.

O estudo também fez transparecer que, em muitas situações, não há equidade na atenção às mulheres em consultas de enfermagem para a coleta de CP. Isso apareceu no emprego de perguntas inapropriadas e na inabilidade interacional para auxiliar as usuárias nas dificuldades com a utilização de termos para tratar de sexualidade. Outro aspecto percebido por meio da microanálise dos dados foi a medicalização em consultas focadas na prevenção que contribui para a criação de dependência química da mulher sem considerar possíveis determinantes socioeconômicos. Por fim, a pesquisa sugere que a consulta para coleta de exame CP pode propiciar a investigação de violência contra a mulher e é, portanto, um local de acolhimento para questões femininas que ultrapassam a esfera biomédica.

A pesquisa ampliou o conhecimento de como as mulheres são atendidas na consulta de enfermagem ginecológica e como os recursos interacionais aparecem nas conversas entre elas. As análises das interações não se esgotaram, já que os diálogos encetados nas consultas eram bastante extensos e outros padrões e sentidos poderiam ser buscados A difusão destes achados e da potência da análise das interações conversacionais junto aos profissionais de saúde coletiva e de enfermagem pode estimular a reflexão dos mesmos sobre os aspectos comunicacionais presentes nas relações clínicas e de cuidado.

\section{Colaboradores}

Todas as autoras trabalharam no artigo. LZ Hesler realizou a coleta dos dados. DNP Andrade realizou a análise do ponto de vista linguístico. SN Meneghel coordenou o projeto. 


\section{Referências}

1. Ayres JRCM. Cuidado e humanização das práticas de saúde. In. Deslandes S, organizador. Humanização dos cuidados em saúde: conceitos, dilemas e práticas. Rio de janeiro: Ed. Fiocruz; 2006. p.49-84.

2. Mehry EE. Em busca da qualidade dos serviços de saúde: os serviços de portas abertas para a saúde e o modelo tecno-assistencial em defesa da vida. In: Cecilio LCO, organizador. Inventando a mudança na Saúde. São Paulo: Hucitec; 1997. p. 117-160.

3. Souza AN, Pitanguy J. Saúde, corpo e sociedade. Rio de Janeiro: Ed. UFRJ; 2006.

4. Loder LL, Jung NM. Análises de fala-em-interação institucional: a perspectiva da análise da conversa etnometodológica. Campinas: Mercado de Letras; 2009.

5. Helman CG. Cultura, Saúde e Doença. $5^{a}$ ed. ed. Porto Alegre: Artmed; 2009.

6. Caprara A, Franco ALS. Relação médico-paciente e humanização dos cuidados em saúde: limites, possibilidades, falácias. In: Deslandes S, organizador. $\mathrm{Hu}$ manização dos cuidados em saúde: conceitos, dilemas e práticas. Rio de Janeiro: Ed. Fiocruz; 2006. p. 85-108.

7. Scott J. Gênero: uma categoria útil de análise histórica. Educação Realidade 1990; 16(2):5-22.

8. Caprara A, Rodrigues J. A relação assimétrica médico-paciente: repensando o vínculo terapêutico. Cien Saude Colet 2004; 9(1):139-146.

9. Ayres JRCM. Da necessidade de uma prática reflexiva sobre o cuidado: a hermenêutica como acesso ao sentido das práticas de saúde. In: Pinheiro R, Mattos RA, organizadores. Razões públicas para a integralidade em saúde: o cuidado como valor. $2^{\mathrm{a}}$ ed. Rio de Janeiro: IMS/UERJ/Abrasco; 2009. p.127-144.

10. Job CM. Coleta de exame citopatológico: espaço de estudo de queixas sexuais [dissertação]. São Leopoldo: PPG Saúde Coletiva; 2004.

11. Meneghel SN. Equidade de gênero nos serviços de saúde como um marcador de integralidade na Atenção Básica [projeto de pesquisa]. Porto Alegre: UFRGS; 2012.

12. Ostermann AC, Andrade D, Frezza M. A prosódia como componente de formação e atribuição de sentido a ações na fala em interação - o caso de formulação no tribunal. DELTA 2016; 32(2):481-513.

13. Steensing J, Larsen T. Affiliative and desaffiliative uses of you say x question. Discourse Studies 2008; 10(1):113-133.

14. Shegloff E. Sequence organization in interaction - a primer in conversation analysis. Cambridge: Cambridge University Press; 2007.

15. Mondada L. Working with vídeo: how surgeons produce video records of their actions. Visual Studies 2003; 18(1):58-72.

16. Ostermann AC, Rosa DR. Do que não se fala: assuntos tabus e momentos delicados em consultas ginecológicas e obstétricas. In: Ostermann AC, Meneghel SN, organizadores. Humanização Gênero Poder: contribuições dos estudos da fala-em-interação para a atenção em saúde. Rio de Janeiro: Fiocruz/Mercado de Letras; 2012. p. 47-64.

17. Silva CR, Andrade DNP, Ostermann AC. Análise da Conversa: uma breve introdução. ReVEL 2009; 7:13.

18. Gago PC. Questões de transcrição em análise da conversa. Veredas 2002; 6(2):89-113.
19. Ostermann AC, Meneghel SN. Humanização Gênero Poder: contribuições dos estudos da fala-em-interação para a atenção em saúde. Rio de Janeiro: Fiocruz/Mercado de Letras; 2012.

20. Enfield NJ, Sidnell J. The concept of action. Cambridge: Cambridge University Press; 2017.

21. Bolinger D. Interrogative structures of American English. Publications of the American Dialect Society, 28. Tuscaloosa: University of Alabama Press; 1957.

22. Salvatti Paim MH. Marcas no Corpo: gravidez e maternidade em grupos populares. In: Duarte LFD, Leal OF, organizadores. Doença, sofrimento, perturbação: perspectivas etnográficas. Rio de Janeiro: Editora Fiocruz; 1998. p. 31-47.

23. Sacavone L. Dar a vida e cuidar da vida: sobre maternidade e saúde. REDEH 1991; 2:127-186.

24. Hayano K. Question design in conversation. In: Sidnell J, Stivers T, organizadores. The handbook of conversation analysis. Oxford: Blackwell Publishing; 2013. p. $400-410$.

25. Bolden G. Beyond answering - repeat-preface responses in conversation. Communication Monographs 2009; 76(2):121-143.

26. Wong J. Repetition in conversation - a look at "first and second sayings". Res Language Soc Interaction 2000; 33(4):407-424.

27. Tesser CD. Medicalização social (I): o excessivo sucesso do epistemicídio moderno na saúde. Interface (Botucatu) 2006; 9(18):61-76.

28. Biglia B, San Martin C. Estado de Wonderbra. Entretejiendo narraciones feministas sobre las violencias de gênero. Barcelona: Vírus editorial; 2007.

29. Schualm SR. Usos do marcador discursivo né em interações médico-paciente [tcc]. São Leopoldo: Universidade do Vale do Rio dos Sinos; 2014.

30. Meneghel SN. Efeitos emocionais das violências de gênero. In: Fleury-Teixeira E, Meneghel SN, organizadores. Dicionário feminino da infâmia. Acolhimento e diagnóstico de mulheres em situação de violência. Rio de Janeiro: Fiocruz; 2015. p. 115-117.

31. Romito P, Molzan Turan J, De Marchi M. The impact of current and past interpersonal violence on women's mental health. Soc Sci Med 2005; 60(8): 1717-1727.

32. D'Oliveira AFPL; Schraiber LB. Mulheres em situação de violência: entre rotas críticas e redes intersetoriais de atenção. Rev Med 2013; 92(2):134-140.

33. Davis-Floyd R. The technocratic, humanistic, and holistic paradigms of childbirth. In: International Conference on Humanization of Childbirth. Fortaleza, Brazil, 2-4 November 2000. p. 5-23.

34. Boltanski L. As classes sociais e o corpo. Rio de Janeiro: Paz e Terra; 2004.

Artigo apresentado em 28/10/2018

Aprovado em 08/04/2019

Versão final apresentada em 10/04/2019

Editores chefes: Romeu Gomes, Antônio Augusto Moura da Silva 